\title{
ARTICLE \\ Thorstein Veblen on economic man: toward a new method of describing human nature, society, and history
}

\author{
Noriko Ishida ${ }^{1}$ (D)
}

Received: 12 September 2020 / Accepted: 3 December 2020 / Published online: 12 January 2021

(c) The Author(s) 2021

\begin{abstract}
The fact that Veblen was a keen critic of the neo-classical concept of "economic man" is well known. However, the following issues have not been discussed in enough depth: how he rebuilt the traditional theory of human nature through his new methodology of economics, how much his methodological revision broadened the scope of economics, and what kind of phenomena Veblen's economic theory elucidates. This article examines these issues and aims to show the logical connection between Veblen's controversial proposal on the methodology of economics and his analysis of economic phenomena. Specifically, it reconsiders Veblen's analysis of economic action using a unique concept of instincts, his logic of explaining the relation between society and human nature, his way of drawing history from the relativistic worldview, and his characteristic method of grasping the cause and effect of economic phenomena. Finally, it highlights the importance of modifying the concept of "economic man" by focusing on the qualitative aspect. Particular reference is made to the economic concepts of utility, efficiency, and intangibility.
\end{abstract}

Keywords Economic man · Human nature · Qualitative · Utility · Efficiency · Intangibility

JEL Classification B15 · B31

\section{Introduction}

Since its emergence, the field of economics has addressed the mechanisms of the production, exchange, and distribution of wealth. The question arises as to what the prime mover of these mechanisms is. Thorstein Veblen (1857-1929) would, without

Noriko Ishida

ishida.noriko@nihon-u.ac.jp

1 College of Economics, Nihon University, 3-2 Kanda-Misakicho 1-chome, Chiyoda-ku,

Tokyo 101-8360, Japan 
hesitation, have replied that it is not the invisible hand of God or the providence of nature, but human existence.

Veblen, who was a keen critic of orthodox economics, coined the term "neo-classical." Concerning the subject of human action, a pivotal change in the history of economic thought occurred with the abstraction of the human model, and it accelerated such a movement during the last quarter of the nineteenth century. Since the neo-classical human model was precisely uniform, economists developed a highly mathematical description of the human being. As a result, economics assumed a position equivalent to natural science. However, some schools, such as the German Historical School, warned against the acceptance of the abstract human model and called for the redefinition of the scientific method of economics; some scholars of the United States were in agreement. Veblen, a post-Darwinian scientist, was one of them. He was convinced of the need to replace the excessively abstract neo-classical model of human nature with a more matter-of-fact formulation of human action, and therefore adopted not only a brand-new method of interpreting non-teleological historical processes but also the original way of acknowledging the active, or teleological, action of human beings. ${ }^{1}$ Needless to say, his attempt included the Kantian methodological approach to teleology. Veblen examined the widely accepted methodology of economics and suggested its "rehabilitation" (EW Jorgensen and HI Jorgensen 1999, 194; Veblen 1919, 56) in the post-Methodenstreit age of the late nineteenth century.

How do we describe a human being in economics? The previous debate on this issue focused on whether Veblen's critique of "economic man" would mean the assertion that economics must accept the more realistic human model. Most scholars responded in the affirmative to this interpretation. Jensen (1987) argued that in addition to Veblen, a long list of institutional economists subscribes to the approach of the pursuit of reality when describing human nature as one of the common theoretical characteristics. However, Veblen's assertion implies more than that. The principal difference between Veblen and others is a unique idea of instincts at the core of the theory of human nature. According to Mayberry (1969), Veblen's hidden normative point of view is embedded in his idea of human instincts. A normative model of economic society would be described by the intermediary of the concept of instincts; for example, a sense of value to "make directly for the material welfare of the community" (Veblen 1914, 25) would be implanted in the instinct of workmanship, while a sense of parental bent would have "a large part in the sentimental concern entertained by nearly all persons for the life and comfort of the community at large, and particularly for the community's future welfare" (Veblen 1914, 27). However, great care should be taken in interpreting Veblen as the value-neutral scientist typified by Samuels (1990). Such a position implies that Veblen's value judgment

\footnotetext{
1 Since the beginning of his career, Veblen had examined the principles of human thought and action. For example, he devoted himself to the study of Kantian epistemology—particularly the third critique, the Kritik der Urteilskraft (1790)_-in his late 20s, completing his doctorate in 1884.
} 
should not be included in his historical perspective and future forecast, just as there is no implication of progress or excellence in the Darwinian concept of evolution. ${ }^{2}$

An issue unexpectedly received scant attention in the previous studies on Veblen. For instance, Jensen (1987) regarded the institutionalists only as methodological opponents of orthodox economics as it treated the difference from neo-classicals as very crucial. Meanwhile, the argument of Samuels (1990) focused entirely on the scientific methodology as it stressed his image of a rigorous scientist. Moreover, Mayberry (1969) was certainly a socio-philosophical consideration as it tried to extract the "ideal of human behavior," or a kind of "moral framework" from the world Veblen drew (322). Although all of these interpretations appear persuasive, there is no obvious answer concerning which of them is correct. However, in a strict sense, these studies are not from the standpoint of economics or economic methodology. ${ }^{3}$ Therefore, identifying the type of "economic phenomena" on which Veblen's revised explanatory model for economic action could successfully shed light would still be an open question.

In this paper, the examination of this problem does not intend to contradict the existing interpretations. It merely attempts to explain the implications of Veblen's critique of neo-classical economics with the inclusion of a comprehensive review of his theoretical results. In other words, this study examines his methodology of economic science ${ }^{4}$ together with his analysis of the economic society of the day in works such as The Theory of the Leisure Class (Veblen 1899), The Theory of Business Enterprise (Veblen 1904), The Instinct of Workmanship and the State of the Industrial Arts (Veblen 1914), and The Engineers and the Price System (Veblen 1921). Previously, both his methodology and his analysis of economic phenomena were often discussed separately. Therefore, perhaps surprisingly, a conscious attempt at understanding his contribution to both fields together is still to be made.

This study aims to examine Veblen's ambitious methodology from three specific perspectives - the theory of human nature, the view of history, and the concept of causal cognition. The remainder of the paper is organized as follows. Section 2, which deals with Veblen's theory of human nature, examines the meaning of his analysis of economic action using a unique concept of instincts. In his methodology, the human model, which is given a sociality by instinct, dynamically renovates the interpretation of society to form a worldview that can relativize the historical process. Section 3 discusses his logic, and the study shows that the Veblenian model of economic action is in sharp contrast to orthodox economics. Finally, Section 4 presents that Veblen's methodology of economic science, based on his theory of human nature and view of history, was original in that he recognized the causal relationship between economic phenomena focusing on the facts belonging to the qualitative category.

\footnotetext{
${ }^{2}$ Regarding the image of Veblen as an evolutionist, there is no single answer. According to Tilman (2007), Veblen's view of human nature is closely linked to his evolutionary naturalism and secular humanism.

${ }^{3}$ Exceptionally, Rutherford (1996) detailed the methodological difference between old and new institutional economics.

4 Most of them were collected in Veblen (1919).
} 
The purpose of this article is, from the perspective of economics or economic methodology, to identify the economic phenomena that Veblen's revised model of human nature successfully explains. As a conclusion to this study, the reason that the concept of "economic man" should be modified is, according to Veblen, because we need to examine economic phenomena from the viewpoint of the qualitative category to overcome the limitations of the traditional neo-classical model. In doing so, we can grasp the problem of value concerning people's actual utility or happiness, deeply examine the various aspects of differences in efficiency, and broaden the possibility of interpreting capital, assets, cost, technology, and knowledge in society.

\section{Reconsidering the theory of human nature}

Veblen's broad knowledge of anthropology is the most notable aspect of his texts. We find a variety of habits of thought, actions, or institutions of people with diverse cultural backgrounds in time and space. In the opening of the first chapter of The Theory of the Leisure Class, Veblen discusses the emergence of the institution of the leisure class and lists typical examples including feudal Europe and Japan, the Indian caste system, the Polynesian distinctions of occupation, the Icelandic community in the time of the Sagas, and the North American hunting tribes. He subsequently references the tribes of the Andamans, the Todas of the Nilgiri Hills, the Ainu of Yezo, Bushman, and Eskimo groups (Veblen 1899, 1-8), and emphasizes that the difference between cultures created the institution of the leisure class and others without having its institution formerly specified. For instance, Veblen's most famous term is "conspicuous consumption," which was illustrated by the potlatch of the Indians (Veblen 1899, 75). In this way, he used a felicitous strategy in an efficient manner to compare the past schemes of life in the history of civilization, linking them with modern phenomena.

However, the concept of using anthropological knowledge was not new because Karl Marx (1818-1883) and Friedrich Engels (1820-1895), ${ }^{5}$ as well as the German Historical School, had already accessed huge amounts of historical data. Even the leading authority on neo-classical economics at that time, Alfred Marshall (1842-1924), showed deep concern for anthropology or economic history. Nevertheless, Veblen did not only use these materials but also tried to reconstruct a psychological model explaining economic behavior. ${ }^{6}$

\footnotetext{
5 For more details, see Bloch (1983).

${ }^{6}$ It can be an appropriate interpretation that anthropology, as well as evolutionary biology, was a popular academic field for scholars in the mid-nineteenth century. Veblen caught the inner stirrings of it when he studied at Carleton College because the young German-trained John Bates Clark (1847-1938) lectured there-not only on "Political Economy," but also on the "History of Civilization." According to the Carleton College Archives, Veblen attended both lectures in his busy final year (1879-80), when he graduated by skipping the junior year (Hillemann 2004, Appendix B-1). Stabile (1997) noticed that Clark was interested in "an anthropological approach to economics" when he taught at Carleton College from 1877 to 1880 . He drew attention to the fact that the marginalist approach that Veblen criticized was
} 
What type of psychology should we adopt in place of traditional hedonism? This question can be addressed from the methodological viewpoint because it requires reconsidering the human model of "a lightning calculator of pleasures and pains" (Veblen 1919, 73), which has been postulated in economics as a sound image for many years. The following correspondence ${ }^{7}$ between Veblen and his close friend Sarah $\mathrm{Hardy}^{8}$ enables a better understanding of his methodological position at that time.

My theory touches the immediate future of the development of economic science, and it is not so new or novel as I make it out to be. It is to the effect that the work of the generation of economists to which you belong is to consist substantially (so far as that work is to count in the end) in a rehabilitation of the science on modern lines. Economics is to be brought into line with modern evolutionary science, which it has not been hitherto. The point of departure for this rehabilitation, or rather the basis of it, will be the modern anthropological and psychological sciences, perhaps most immediately, for economic theory in the general sense, that folk psychology which is just now taking on a definite form. Starting from this preliminary study of usages, aptitudes, propensities and habits of thought (much of which is already worked out in a more or less available form) the science, taken generally, is to shape itself into a science of the evolution of economic institutions.

His recognition of the state of economics was formed under the hard eyes of the post-Methodenstreit generation. ${ }^{9}$ For Veblen, the anthropological knowledge of the

\footnotetext{
Footnote 6 (continued)
}

not the economics that Clark had taught Veblen at Carleton College. Stabile (1997) considered Clark's explanation of history too rudimentary for Veblen. According to him, Veblen turned Clark's topics, such as "showy consumption as a corruption of higher wants," upside down. The textbooks for Clark's "History of Civilization" in the academic year 1879-80 were George Weber's Outlines of Universal History: From the Creation of the World to the Present Time, Frederic Butler's A History of the United States of America, and François Guizot's The History of Civilization in Europe (Carleton College, 1880, 23).

7 Letter from Thorstein Veblen to Sarah Hardy, January 23, 1896. (EW Jorgensen and HI Jorgensen 1999, 194).

8 According to Dorfman ([1934] 1972, 132-133), Sarah Hardy was one of Veblen's best friends at Chicago University. From their letters, we can gather information on the progress of writing The Theory of the Leisure Class (1899) and his great interest in anthropological studies. Whole texts of their correspondence are contained in EW Jorgensen and HI Jorgensen (1999), which also shows their personal relationship in the 1890s. Their friendship continues after this period. Lucy Mitchell, Wesley Clair Mitchell's wife, looks back on the days in California. Some intellectuals like Allyn A. Young and Franklin L. Lane, in addition to Veblen and Sarah, enjoyed the social and intellectual circle of the Mitchells. According to Lucy, it was "real friendships—not just sociability" (Mitchell 1953, 151).

9 Regarding the Methodenstreit, Veblen had a sharp tongue against both camps. He made the following remarks in the same letter. "It might also be argued that this was the meaning of the movement called the Historical School; but the Historians failed to recognize their vocation and ran off into inanities. On the other hand, the Austrians and their followers in other countries have been groping out instinctively and blindly into the domain of psychology, and trying to find there the premises and justification of their theories, but as they were out of date in their psychology, besides not knowing what they were about, the result has not had the value which it otherwise might. However, and this is to the point even if the rest is not, a reading of some of the books that deal with anthropology in outline would never come amiss whether the growth of the science takes on direction or another" (EW Jorgensen and HI Jorgensen 1999, 195). 
day was central to his plan for the "rehabilitation" of economic science. Though he had absorbed a good deal of knowledge from the rather old fields of medicine and phrenology since the early nineteenth century, ${ }^{10}$ it was also obvious that he learned from the new achievements in ethology and social psychology at that time, in addition to the latest results in cultural anthropology from Edward Tylor to Franz Boas. This is evident in his citation of the famous anthropo-sociologist, Georges Vacher de Lapouge (1854-1936): "Anthropology is destined to revolutionise the political and the social sciences as radically as bacteriology has revolutionised the science of medicine" (Veblen 1919, 56).

The concepts of instincts and habits are central to Veblen's model interpreting economic action. Habits are assumed to be a norm of conduct on which everyone relies, from village people in a primitive barbarian culture to city dwellers in a civilized nation. Veblen uses the examples of the King of France who chose to be burned to death at the royal throne instead of escaping (Veblen 1899, 43), and of a Polynesian chief who preferred to starve rather than carry his food to his mouth with his hands (Veblen 1899, 42). In this way, he drew attention to the fact that some cultural habits - in these cases, as a tabu — could override the basic instinct for self-preservation. On the other hand, while referencing the urban woman clothed in a beautiful dress, he interpreted the practice as a modern-day habit to keep up with the latest fashion. Such an understanding of habit is perhaps heterogeneous from the standpoint of classical and neo-classical economists, who believed that liberation from old habits enables people to improve political and economic liberty and leads to civilization.

The concept of instincts is characteristic of Veblen's analysis of human action, although focusing on this concept has been "a minor issue in the literature about institutional economics" (Almeida 2015, 227). Veblen's emphasis on instincts was extraordinary because the term "instinct" was already outdated in the field of biology. Interestingly, Veblen selected the term despite his familiarity with this trend in the sciences.

A genetic inquiry into institutions will address itself to the growth of habits and conventions, as conditioned by the material environment and by the innate and persistent propensities of human nature; and for these propensities, as they take effect in the give and take of cultural growth, no better designation than the time-worn "instinct" is available. (Veblen 1914, 2-3).

In Veblen's theory of human nature, there is a reciprocal relationship: habits originate from instincts, and they form under the effect of instincts while, at the same

\footnotetext{
10 Veblen's interest in medicine and phrenology can be gauged from the letter to Sarah Hardy, who was encouraged by him to read books, most of which were works by French authors; and his interest in ethnology and social psychology, from citations and references in Veblen (1914). According to Carleton College Archives, we can also see it from the book lineup of Veblen's Washington Island library, which included the annual report of Smithsonian Institution (1881-1902), five books of Jacques Loeb, who was a German-born American physiologist and biologist and his colleague at the University of Chicago, Darwin's Descent of Man and so on. From 1896 to 1926, Veblen spent his summer vacations in his study cabin on Washington Island, a small island on Lake Michigan located in Door County, Wisconsin.
} 
time, controlling instinctive action. In fact, both factors are ill-defined; instincts and habits are two facets of the principles driving human action. ${ }^{11}$

Note that instincts were not considered the antonym of intelligence. According to Veblen, "within the purview of the social sciences," the concept of instincts is not sufficient to be defined or described "in mechanical terms" because it belongs to "teleological categories" (Veblen 1914, 3, 4, 3).

Many students of animal behaviour are still, as psychologists generally once were, inclined to contrast instinct with intelligence, and to confine the term typically to such automatically determinate action as takes effect without deliberation or intelligent oversight.... If all such preconceptions of a substantial dichotomy between physiological and psychological activity be abandoned it becomes a matter of course that intellectual functions themselves take effect only on the initiative of the instinctive dispositions and under their surveillance, and the antithesis between instinct and intelligence will consequently fall away. (Veblen $1914,30 n$ ).

We find from such a context that Veblen viewed the following three aspects of human nature as continuous, namely a tropismatic function, a physiological reaction, and a psychological activity. The first is related to reflex, just like the flower turns to face the sun; the second is fundamental to living things in general-briefly, instincts in the narrow sense-and the third is a psychological activity including intelligent thoughts and actions.

What, then, did Veblen intend with his reconsideration of psychological premises? These had not changed since the 1890s when Veblen began to discuss the methodology of economic science. Simply put, Veblen was criticizing the concept that the human nature of the neo-classical school-the hedonistic conception of man, or in other words, the economic man-is described only as "passive and substantially inert" (Veblen 1919, 73). According to his interpretation, "while hedonism seeks the causal determinant of conduct in the (probable) outcome of action, the later conception seeks this determinant in the complex of propensities that constitutes man a functioning agent, that is to say, a personality" (Veblen 1919, 156). The passive human and the active human, both human models, are in sharp contrast.

However, Veblen was not satisfied merely by the assumption of an active human model. To understand the implied meaning, we recall that Veblen's concept of instincts involved intelligence. According to Veblen, "as all men habitually act under the guidance of instincts, and therefore by force of sentiment instinctively look to some end in all activity" (Veblen 1914, 54), and "all instinctive action is intelligent and teleological" (Veblen 1914, 32). Therefore, the instinctive action of a human could not fit the confines of "the category of automatism" (Veblen 1914, 31). At the same time, Veblen took a path toward the content of human purposes. Essentially, an individual is "an agent, seeking in every act the accomplishment of some concrete, objective, impersonal end." Therefore, that individual has "a sense of the merit

\footnotetext{
11 Veblen do not always used the term "instinct." It was restated freely in other ways such as propensity, sense, sentiment, attitude, animus, proclivities, aptitudes, and bent.
} 
of serviceability or efficiency and of the demerit of futility, waste, or incapacity" (Veblen 1899, 15). This propensity is what Veblen called the instinct of workmanship. Building reputation and obtaining respect from others as well as avoiding criticism and disrepute become hallmarks of efficiency or an emulative demonstration of force because of the presence of instinct. This fundamental principle of human nature remains unchanged, although the times and spaces change. The methods to outwit the competition are varied. Veblen devoted himself to historically tracing the teleological aspect - that is, the ends and means - of human beings. In doing so, Veblen deciphered the Darwinian theory of natural selection, not as a competitive mechanism of environmental determinism, but as a cultural structure of interpersonal emulation, inserting human adaptivity in a vivid way. ${ }^{12}$

Veblen did not consider that this most fundamental propensity, that is, the instinct of workmanship, could provide the only accurate reflection of human nature. Subsequently, several human instincts are discussed in Veblen's text. The instinct of workmanship is considered one of the "instinctive dispositions that conduce directly to the material well-being of the race, and therefore to its biological success" (Veblen 1914, 25); the parental bent is competing for the top position in this regard. This bent gives the same attention to future generations as the general parental relation and holds enormous potential to resonate with the instinct of workmanship, which places importance on the serviceability and efficiency of society. However, these two instincts do not always lead to good actions socially. For example, linking these instincts with the predatory instinct could bring about war and slaughter in communities. Veblen introduced different types of instinctive proclivities, for instance, the patriotic sentiment in disputes on war and peace, or the idle curiosity in the context of the history of science. However, Veblen's purpose was not to represent a universal definition, catalog and list their characteristics, or judge the good and evil or right and wrong of definitions. With an assumption that plural instincts coexist and intertwine, the accuracy of Veblen's human model in his economic history of civilization is guaranteed. His interest is to note "how and with what effect the several instinctive proclivities"-various purposes of the human-“cross, blend, overlap, neutralise or reënforce one another"13 (Veblen 1914, 8-9). Veblen interpreted individual instincts as an unchangeable propensity to some extent, while human nature, which is complex, may have the capacity to vary. Veblen analyzes or describes human action matter-of-factly using such methodological logic. According to Veblen, a realistic standpoint - matter-of-fact understanding of the causal relation of human action - is a necessary spiritual attitude for modern scientists (for example, David Hume), and a methodological basis underlying evolutionary economics (Veblen 1919, 97). Veblen thought, "the anthropological survey should give a view

\footnotetext{
12 Although previous studies of Veblen's economic thought highlighted only his emphasis on non-teleological history or worldview in his criticism of natural law or Spencerian evolutionism, it is more appropriate to state that Veblen tried not to dismiss teleology but to modify it in terms of the theory of action. This represented the remnants of his study during his younger days on Kant's third Kritik, which was composed of two parts: critique of aesthetic judgment and of teleological judgment.

13 Additionally, concerning the combination of instincts, Veblen used the expression "contamination.".
} 
of man in perspective and more in the generic than is ordinarily attained by the classical economist, and should give added breadth and sobriety to the concept of 'the economic man.",14

Based on the cultural structure of interpersonal emulation, many instincts exist together in a single person. Veblen's revised proposition paved the way for another problem that hedonistic psychology tended to overlook. This was the problem of how to embed human sociality in the model that explains human action.

\section{Human sociality and dynamics of society}

Veblen's model of economic action is, as Mason (1998) traced precisely, ${ }^{15}$ characterized by a strong emphasis on the presence of others or human sociality. The model of economic action based on sociality contradicts the individualistic image of "economic man," according to which a solitary man can maximize utility under the given condition. However, in Veblen's view, a human is neither a passive reacting being, such as an animal tempted by mere pleasure or utility, nor a machine.

Then, too, the phenomena of human life occur only as phenomena of the life of a group or community; only under stimuli due to contact with the group and only under the (habitual) control exercised by canons of conduct imposed by the group's scheme of life. (Veblen 1919, 242).

What is the utility of a spoon? Does its utility lie in its price or functionality? Does its utility depend on whether it is machine-made or craftsman-made? Does the spoon's utility depend on the consumer's desire to display social stature, for example, by selecting a silver spoon ${ }^{16}$ We know that the motive to buy would differ greatly in individuals, even if an item is the same. Moreover, the decision to buy is not just an individual act, but one that is controlled by social custom. Such a view surmises the motives of action or the content of utility. This would be an absurd idea, from the standpoint of Lionel Robbins (1898-1984), who objected to making an interpersonal comparison of utility. However, Veblen tried to focus on the inward aspects of the human mind using his concept of instincts and habits, despite the fact that they were invisible and unmeasured. ${ }^{17}$

\footnotetext{
${ }^{14}$ Letter from Thorstein Veblen to Sarah Hardy, February 6, 1896. (EW Jorgensen and HI Jorgensen 1999, 196-197).

15 Mason (1998) positions his theory of conspicuous consumption focusing on the interpersonal effect as the first attempt at a caustic critique of the neo-classical school of consumer theory.

16 The case of the spoon is an argument in Chapter 6 "Pecuniary Canons of Taste" of Veblen (1899). Veblen provided examples of consumption where the "economic man" hypothesis could not address, for instance, the lawn, pet animals, the visible imperfections of hand-wrought goods such as those that John Ruskin and William Morris adored, books with uncut pages, black-letter publications, and candlelight after electricity became familiar.

${ }^{17}$ As to "a multilayer structure" reflecting the cumulative process of evolution in Veblen's concept of human nature, See Taka (2003).
} 
The term "instinct" is typically perceived as implying a self-regarding disposition to seek individual benefit. Thus, the argument below may seem strange. For example, the previously mentioned parental bent is oriented toward the benefit of others because it also considers the next-generation members of society. Further, the instinct of workmanship is also given a similar function. As noted, the instinct is linked with a contribution to the material well-being of humankind and its general purpose. Given that both instincts concern increasing benefits and maintaining the public good of society, they can be regarded as human capability from an altruistic point of view, and the term "instinct" seems inappropriate.

Additionally, it is striking that Veblen postulated human sociality as referring to both altruistic action and self-regarding action. For instance, the instinct of workmanship, which appears to be an altruistic and, therefore, cooperative instinct, was paradoxically the source of a habit of invidious comparison of the self with others. The presence of others is indispensable for the habit of invidious comparison. It is a social relation; strictly speaking, it involves interactions of emulation while pursuing self-regarding aims. To cite a case, mutual emulation may enable humans to invent tools serviceable to the community and innovate technologies. However, emulation, which may incur envious sentiment in some cases, will sow the seeds of conflict. The reason people consume goods and services conspicuously is to display their ability to spend. However, the observer may experience longing or respect, and it may turn to jealousy. Veblen addresses an action with more negative emotions than envy. He assumed the pugnacity and predatory disposition to be instinctive and that such actions would be performed without the presence of others. ${ }^{18}$ Thus, regardless of self-regarding or altruistic actions, Veblen's supposition of a cultural structure of interpersonal emulation presupposes human sociality.

Therefore, an essential element of Veblen's evolutionary economics became the examination of the effect of instincts pursuing various ends because they would drive the human action even in the economic activities of consuming, producing, selling, and marketing. From this perspective, Veblen criticized the hedonistic human model of neo-classical economics obviously not because it assumed an unreal self-regarding individual. Veblen described as the most typical human model a self-regarding man who has a passion for conspicuous consumption and maximum utility and profit. However, the biggest problem was that neo-classical economics ignored the sociality of both the self-regarding and altruistic individual.

Veblen placed weight on the variety of human actions, which complies with the cultural relativistic perspective.

Not only is the individual's conduct hedged about and directed by his habitual relations to his fellows in the group, but these relations, being of an institutional character, vary as the institutional scheme varies. (Veblen 1919, 242).

Veblen arrives at a perspective that permits the diversity of human nature and, at the same time, encompasses diversified cultures and society historically and geographically. The concept of habit, then, like that of instinct, is a logical apparatus to

$\overline{18}$ Cf. the instinct of pugnacity (Veblen 1914, 32), the predatory instinct (Veblen 1899, 29). 
share the social norms of the action and thought. Therefore, it is rational that Veblen, deeply committed to evolutionary theory and anthropology, tried to undertake the dual task of reconstructing the psychological ground and introducing the dynamic ground. We find a methodological connection between constructing a human model and tracing history. In other words, Veblen considered that the pursuit of describing human nature leads to the cognizance of the human as an active (teleological, in his terms) and social being. Thus, a logical structure of the dynamic state of society and history emerges. As a result, Veblen easily dismissed a static equilibrium approach. $^{19}$

Veblen's theory of human nature, using a concept of instincts, includes a proposal to rethink the methodology of economics in describing humans, society, and history, specifically by remodeling economic action subsuming human sociality, and rewriting a history of civilization. However, the following question is still open for investigation: what kind of phenomena does Veblen's economic theory elucidate through a revision of methodology? In the next section, we discuss Veblen's new direction in the field of causal cognition toward such a revision. To begin with the conclusion, the dynamism Veblen described was not statistical or metrical dynamism, which the next generation of students, such as Wesley C. Mitchell, dealt with. This is because Veblen emphasized the necessity of the causal relation of economic phenomena in terms of the qualitative category.

\section{Complementing causal cognition with qualitative category}

In the latter half of the nineteenth century, the economic analysis focused on values measured quantitatively, given the ongoing period of the mathematization of description. For example, Alfred Marshall admitted the importance of considering the human variety and economic habits calling attention to the existence of economic motives that are not always self-regarding. Marshall's view is no different from Veblen's. However, Marshall considered that economics should confine the subject of human motives to "a definite amount of money" because "no one can measure the mental states of another at all except indirectly and conjecturally by their effects." Additionally, it is "the advantage which economics has over other branches of social science" (Marshall [1890] 1961, 14-15). This point of view is the same as that of one of Marshall's disciples, Arthur C. Pigou (1877-1959). According to Pigou, "full guidance for practice requires, to borrow Marshall's phrase, capacity to carry out quantitative, not merely qualitative, analysis [italics by Pigou]." Therefore, "the range of our inquiry becomes restricted to that part of social welfare that can be brought directly or indirectly into relation with the measuring-rod of money" (Pigou [1952] 2002, 8, 11). However, is it appropriate that economics could have an advantage over other social sciences because it addresses the quantitative category?

\footnotetext{
19 The context of the dynamic approach was appreciated to a greater extent than the static approach in Veblen's text. For example, in 1909, Veblen discussed John B. Clark's statics in his article "The limitation of marginal utility."
} 
Veblen questioned the preconception of mainstream economists. Meanwhile, Marshall and others treated it as a positive strength, whereas Veblen considered it a fatal limitation.

Veblen's insistence was that economists should be concerned with more than the quantitative category. His criticism of John Bates Clark, his contemporary and former teacher at Carleton College, is illustrative. ${ }^{20}$

the hedonistic postulate and its propositions of differential utility neither have served nor can serve an inquiry into these phenomena of growth, although the whole body of marginal-utility economics ${ }^{21}$ lies within the range of these pecuniary phenomena. It has nothing to say to the growth of business usages and expedients or to the concomitant changes in the principles of conduct which govern the pecuniary relations of men, which condition and are conditioned by these altered relations of business life or which bring them to pass. (Veblen $1919,233)$.

The problem of whether economics should narrow down a subject to a quantitative object is not independent because it coexists with other methodological problems on how to deal with technological development, various motives of business enterprises and consumers, and diversity in social customs and habits, all of which are hard to explain by the quantitative category. Here, Veblen steered himself in the opposite direction to orthodox economics.

If we observe only the causal relations regarding the quantitative category, the arguments concerning the qualitative relation tend to be overlooked. Value theory is a good example; it is reduced to the theory of price. Strictly speaking, as Marshall's case provides, although he sufficiently realized the importance of qualitative value in economics, he was remiss not to treat this value.

While referring to W. Sombart's Der moderne Kapitalismus (Veblen 1904, $366 n-367 n),{ }^{22}$ Veblen argued two conceptions of the causal relation in modern science from the eighteenth and early nineteenth centuries. One is the equality of cause and effect, or quantitative equivalence; the other is the similarity of cause and effect, or qualitative equivalence (Veblen 1904, 364). In Veblen's understanding, "the former has come practically to signify the balanced articulation of the process of cumulative change; the endeavor of the Positivists to erect this canon of quantitative equivalence into the sole canon of scientific truth, and so to reduce scientific theory to a system of accountancy, having failed" (Veblen 1904, 370-371). In

\footnotetext{
${ }^{20}$ Veblen discussed Clark in this context. Clark published The Essentials of Economic Theory, as Applied to Modern Problems of Industry and Public Policy in 1907. Veblen's interest in this book was intense. He contributed a book review in the Quarterly Journal of Economics and severely criticized the work. The argument of this article is viewed as a continuation of the article.

21 The economist who is known for "marginal-utility economics" depends on the context. It often refers to Marshall or Clark, and the term is usually a synonym for "neo-classical economics" or "neo-classical political economy." Additionally, Veblen $(1914,46)$ referred to Pantaleoni's Pure Economics.

22 According to Veblen, Sombart finds the modern scientific concept of cause and effect to be essentially an outcome of the discipline of accountancy enforced by business traffic. Veblen tried to add his interpretation critically into Sombart's view as we will discuss.
} 
addition, Veblen thought that the latter thesis had also fallen into decay, as far as it related to harking back to the "first cause" or the "Great Artificer" (Veblen 1904, 365) and explaining that "the cause controls, determine the effect by transmitting its own character to it" (Veblen 1904, 365-366). According to Veblen, the relation in which the modern scientists begin to have a particular interest included the latter qualitative equivalence, which differed from the cognitions described above. The preceding cognitions appeared "more and more consistently to think in the opaque, impersonal terms of strains, mechanical structures, displacement, and the like; terms which are convertible into the working drawings and specifications of the mechanical engineer" (Veblen 1904, 371).

Veblen's positive evaluation of the qualitative category was consistent throughout his writing career. ${ }^{23}$ It would, however, be premature to conclude that he employed only the qualitative and not the quantitative category. Veblen's point is not that the latter category is unnecessary, but that the former category must complement the latter because significant issues may be overlooked if the only option being considered is the quantitative category (Veblen 1919, 179). Additionally, it would be naive to interpret the qualitative category as merely the antonym of the quantitative category. $^{24}$

Foot-pounds, calories, geometrically progressive procreation, and doses of capital, have not been supplanted by the equally uncouth denominations of habits, propensities, aptitudes, and conventions, nor does there seem to be any probability that they will be; but the discussion which continues to run in terms of the former class of concepts [quantitative category-quoter] is in increasing degree seeking support in concepts of the latter class [teleological category-quoter]. (Veblen 1919, 179).

In Veblen's argument, the causal cognition of the qualitative equivalence is almost equal to concepts of the teleological category, which concerns the principles that explain human action, and includes the internal principles-instincts, propensities, and aptitudes - and the external principles-social relations or habits and conventions. This methodological argument reveals why Veblen judged the neoclassical hedonistic interpretation of man as "out of date" and tried to "give added breadth and sobriety to the concept of "the economic man." Veblen's rehabilitation plan for economic science reconstructed the psychological basis by applying anthropology and biology. What would emerge from this argument is that Veblen intended to reverse the existing approach to causal cognition in economics.

In what manner does Veblen understand the phenomena in his economic analysis focusing on the qualitative equivalence, in other words, the teleological category? To answer this question, the following subsections describe three concepts: utility, efficiency, and intangibility.

\footnotetext{
${ }^{23}$ For instance, Veblen valued J.S. Mill's sophisticated conception of utilitarian hedonism. See Part III of Veblen's article "The preconception of economic science" (1919, 148-179).

24 This is considered the manifestation of his intention to distinguish from the old type of cognition method for qualitative equivalence.
} 


\subsection{Utility}

The first concept is utility, the fundamental concept of neo-classical economics. It is characterized by the theory that man is highly individualistic because economists have placed less emphasis on introducing human sociality into their theory. On the other hand, we have already seen that Veblen's premise of instincts in his model of human action is a logical apparatus with which to describe human sociality.

For example, Veblen listed cases where someone's performance was not always evaluated simply in hedonistic terms. He argued that, along with the development of the monetary economy, when people's faculty of judgment discriminated between respect and dishonor, or superiority and inferiority began to be eroded by the pecuniary culture, the "commercialization" of taste and appreciation occurred. ${ }^{25}$

These "commercial" conceptions of merit and demerit are derived from business experience. The pecuniary tests and standards so applied outside of business transactions and relations are not reducible to sensuous terms of pleasure and pain. (Veblen 1919, 246).

In fact, our ability to judge pleasure and pain or beauty and ugliness significantly affects our economic activity, such as production, consumption, and marketing. If this is true, the principles underlying human action are too complex to explain with the simple dualistic calculation of hedonism. Moreover, honorific evidence may cause envy among observers, who may sometimes experience mental torment. If this proposition is true, in societies where the habits of interpersonal pecuniary comparison prevail, what emotions do those who consume wastefully feel? Can consumers feel pleasure from buying an excess of goods? Regardless of how much they consume, does it ever satisfy their vanity? Is the utility or disutility that they feel considered pleasure or pain? Simply put, are they happy?

Veblen's concept of competition found in pecuniary emulation contains the naked emotions of common everyday life. This is not always the source of the fair deal and the order of justice as the orthodox economists had implicitly assumed. Although everyone would admit that such a qualitative aspect of subjective utility exists, we cannot explain it with the methodology of economics, which is confined to the quantitative category.

\subsection{Efficiency}

The concept of efficiency is interpreted as follows. In general, efficiency is not considered to have more than one meaning. However, it is different in Veblenian terms because he described it in two different ways, namely "industrial efficiency" and "pecuniary efficiency." It is "the instinct of workmanship" to regulate the sense of efficiency. According to Veblen, "the instinct of workmanship brought the life of mankind from the brute to the human plane, and in all the later growth of culture it

25 This example is in the context of his criticism of Clark. 
has never ceased to pervade the works of man" (Veblen 1914, 37). Additionally, as cited above, efficiency signifies "a sense of the merit of serviceability or efficiency and of the demerit of futility, waste, or incapacity" (Veblen 1899, 15) and "chief among those instinctive dispositions that conduce directly to the material well-being of the race, and therefore to its biological success" (Veblen 1914, 25). That is, the efficiency identified by this instinct implies "industrial efficiency." In other words, it is to work without wasted motion like a workman or craftsman, to consider the social serviceability and, subsequently, to enhance productivity. Therefore, it is not "pecuniary efficiency" that is sought by businessmen for profit.

Wherever the pecuniary culture prevails, the selective process by which men's habits of thought are shaped, and by which the survival of rival lines of descent is decided, proceeds proximately on the basis of fitness for acquisition. Consequently, if it were not for the fact that pecuniary efficiency is on the whole incompatible with industrial efficiency, the selective action of all occupations would tend to the unmitigated dominance of the pecuniary temperament. The result would be the installation of what has been known as the "economic man," as the normal and definitive type of human nature. But the "economic man," whose only interest is the self-regarding one and whose only human trait is prudence, is useless for the purposes of modern industry. (Veblen 1899 , 241).

In Veblen's analysis, businessmen attempt to minimize costs to maximize profits as neo-classical economics states. However, for advertising costs, it would be entirely different. According to Veblen, the expenses of advertisement tend to become bloated. Advertising is no doubt "a service to the community" in that it "gives the body of consumers valuable information and guidance as to the ways and means whereby their wants can be satisfied and their purchasing power can be best utilized" (Veblen 1904, 57). However, "in some extreme cases, the cost of competitive selling may amount to more than ninety per cent. of the total cost of the goods ${ }^{26}$ when they reach the consumer" (Veblen 1904, 60). Therefore, the "cost of production" of commodities under the modern business system is "cost incurred with a view to vendibility, not with a view to the serviceability of the goods for human use" (Veblen 1904, 59). In this sense, for Veblen, "business" is not "industry," and investment is not production (Veblen 1921, 145). Workmen's dexterity cultivated in creating something, proprietors' cunning skill to sell a well-known home remedy by spending several million dollars annually in advertisements, and efficiency engineers' abilities ${ }^{27}$ to manage the industrial economy are not uniform. It follows that

\footnotetext{
26 The sufficient ground or source for the statistic of $90 \%$ was not referenced.

27 The "efficiency engineer" is a prototype of the leader of the "Soviet of Technicians" in which Veblen placed his hope in his later works. On a side note, according to Veblen, the "consulting economist" or "production economist," one of the technicians, should participate in "a study of the industrial system considered as a ways and means of producing goods and services" rather than "a theoretical inquiry into the ways and means of salesmanship, financial traffic, and the distribution of income and property" (Veblen 1921, 144-145). Additionally, given that he rephrased "Soviet of Technicians" as "a regime of workmanship governed by the country's technicians" (Veblen 1921, 163), we assume that one of the qualities required to be an efficiency engineer would be the instinct of workmanship.
} 
a unidimensional image of "economic man" is not enough as a tool to explain the real modern economic society. The direction in which every single habit of the mind travels cannot be accounted for by the simple unitary concept of efficiency and the differences cannot be explained quantitatively.

\subsection{Intangibility}

The last concept is the intangibility of assets, capital, and stock. Veblen's arguments present a unique viewpoint in their emphasis on the intangible quality. If capital or wealth were intangible or immaterial, they could not be measured quantitatively. Veblen was the first to understand the seriousness of this value that no one had measured. ${ }^{28}$ For instance, the "good-will" that built the brand image of a business enterprise plays a major role in his business cycle theory. Good-will, according to Veblen, is a type of an intangible asset ${ }^{29}$ and "comprises such things as established customary business relations, reputation for upright dealing, franchises and privileges, trademarks, brands, patent rights, copyrights, exclusive use of special processes guarded by law or by secrecy, exclusive control of particular sources of materials" (Veblen 1904, 139). Good-will ultimately forms the basis of the assessment concerning "capitalized presumptive earning-capacity" (Veblen 1904, 127). Moreover, loan credit-which was increasingly based on the estimated value of the business enterprise, that is, "credit extension" or "competitive recourse to credit"-was becoming common around that time (Veblen 1904, 99). It is easy to understand his analysis from the argument on advertising.

To the extent to which the competitive recourse to credit is of the character here indicated - to the extent to which it is competitive bidding for funds between competent managers - it may be said that, taken in the aggregate, the funds so added to business capital represent no material capital or "production goods." They are business capital, only; they swell the volume of business, as counted in terms of price, etc., but they do not directly swell the volume of the industry, since they do not add to the aggregate material apparatus of industry, or alter the character of the processes employed, or enhance the degree of efficiency with which industry is managed. (Veblen 1904, 99).

\footnotetext{
${ }^{28}$ There is another economist who recognized the idea of intangible assets as an important concept in economics, John Rogers Commons (1862-1945). "Two diverse theories of the modern intangible property have been developed since the year 1890. The one is the exploitation theory of Veblen, the other is the reasonable value theory of the courts. Each is founded on the new idea of property as the present value of future profitable transactions." Commons noted, "Veblen distinguished 'capital' as the value of the corporeal property; but he distinguished intangible value, or intangible capital, as the purely pecuniary valuations by business men, according to their strategic power of holding up the community and 'getting something for nothing.' In this he was correct" (Commons 1934, 649, 650).

29 "Intangible assets" are also described as "immaterial properties" and "immaterial wealth" (Veblen 1904, 117, 139).
} 
Thus, in cases where the discrepancy between business capital and material equipment widens, "a period of liquidation," or the so-called depression begins ${ }^{30}$ (Veblen 1904, 107).

Good-will, as one of the intangible assets, was considered a cause of business cycles and a trigger for the depression. "They [items included in the good-willquoter] are wealth to the individuals concerned—differential wealth; but they make no part of the wealth of nations" (Veblen 1904, 140). Therefore, unless we examine the qualitative aspects of assets, capital, stock, and cost, we cannot elucidate their influence on economic phenomena.

Moreover, the argument for intangibility is not confined to good-will. Veblen's discussion has a broader perspective and extends to the value of technology, art, and knowledge in society or the community. Concerning the traditional argument on factors of production - land, labor, and capital, Veblen added an important factor. Industrial art as "immaterial equipment" (Veblen 1914, 104) is "a joint stock of knowledge" (Veblen 1921, 28).

The state of the industrial art is a joint stock of knowledge derived from past experience, and is held and passed on as an indivisible possession of the community at large. It is the indispensable foundation of all productive industries, of course, but except for certain minute fragments covered by patent rights or trade secrets, this joint stock is no man's individual property. (Veblen 1921 , 28).

Veblen listed this industrial art as a factor of production. If it could not be counted as an individual's property, it is hard to conceive that it would generate income. Additionally, if it cannot be measured as a source that generates income, economists may overlook it as a factor. However, Veblen explained it as follows. Business enterprise controls industrial arts because industrial arts become an essential element for business enterprise to pass the examination for credit loans. However, the money drawn from the possession of intangible assets is not spent on the enhancement or improvement of industrial equipment, and it is rarely divided among the creators of knowledge and technology, who are mostly engineers and workers. In other words, the value of intangible assets is not only one of the causes of the business cycle that threatens the livelihoods of common people. Moreover, the origin of the same value may be concealed. This series of problems are also difficult to apprehend from the perspective of the quantitative category.

We discussed the three examples above. The question now arises on why Veblen complemented the causal cognition with the qualitative category. We noted earlier that his arguments criticized neo-classical economics. According to Veblen, economists of long ago considered that the welfare of the community was regulated "by

\footnotetext{
${ }^{30}$ This description regarding the business cycles in Chapter 5 "The Use of Loan Credit" of Veblen (1904) was published as an article (included in Volume IV of the Decennial Publications of the University of Chicago) in advance of the book's publication.
} 
the skill, dexterity, and judgment with which its labor was generally applied"31 (Veblen 1904, 179). In contrast, the value theory of the neo-classical model addresses only the pecuniary aspects of value although it is just "a theory of a process of valuation" (Veblen 1919, 144). Therefore, in neo-classical economics, "the question of welfare has become a question of price" (Veblen 1904, 177).

Prosperity now means, primarily, business prosperity; whereas it used to mean industrial sufficiency. (Veblen 1904,178 ).

Because of this settled habit of seeing all the conjunctures of life from the business point of view, in terms of profit and loss, the management of the affairs of the community at large falls by common consent into the hands of businessmen and is guided by business considerations. Hence modern politics is business politics.... (Veblen $1904,268-269)$.

When we consider welfare, it is necessary to take into account indexes such as the measures of price or money. However, if we depend exclusively on the quantitative category, we lose sight of the actual content of pleasure and pain in everyday life, the reality of the social relations of the common people, and cannot distinguish the quality of efficiency, that is, industrial or pecuniary. Additionally, we become insensitive to critical problems such as the essence of capital or assets that have been too long neglected because of their intangibility, the value of technology and knowledge, and the exact causes of the depression or recession. According to Veblen, if economics cannot establish the appropriate guidelines to deal with these problems, it would not consider the values squarely.

In Veblen's methodology, if we cannot discuss the confrontation of value that resides in the qualitative or teleological category, economics will regrettably drift into "a theory of valuation with the element of valuation left out, - a theory of life stated in terms of the normal paraphernalia of life" (Veblen 1919, 144). That was Veblen's conclusion. He accepted a non-teleological worldview along the lines of Darwin or Boas and adopted a value-neutral methodology of economic science like that of Samuels' (1990) interpretation. Nevertheless, this paper adds another interpretation. Veblen still believed that economists should recapture some type of value theory. Indeed, Veblen never stated whether a theory was right or wrong, and he never assumed a certain political stance. But he apparently continued discourse unflinchingly, concerning whether a certain economic activity would be wasteful or not-in other words, whether it would contribute to industrial efficiency. At the base of his economic thought was a practical perspective. Therefore, a value theory focused on social welfare was the basis of his rethinking of the human model of economic action.

\footnotetext{
${ }^{31}$ As is commonly known, these are Adam Smith's words in the Introduction of The Wealth of the Nations.
} 


\section{Concluding remarks}

The copious studies on Veblen have interpreted his suggestion of methodological issues in various ways. A type of social philosophical consideration reconstructing his ideal worldview has accumulated steadily, and the outline of his social scientific position under the reinterpretation of Darwinism has been drawn. ${ }^{32}$ For example, it is well known that Veblen effectively criticized the concept of "economic man" because of its unreality and that his criticism of the neo-classical model was notably pungent. However, the issue of determining the types of economic phenomena that Veblen's revised model can explain has been discussed minimally in previous studies. We must explore the core of the problem, which is-what is the conveyed meaning? Accepting the assumption that Veblen's methodology is right, this study answers why the concept of "economic man" should be modified.

The primary purpose of Veblen's evolutionary economics-a rehabilitation plan of economic science-is rebuilding the theory of human nature in economics. However, Veblen's methodological proposition goes far beyond that meaning. As the renewal of the model of economic action paved the way to describe society historically, Veblen could depart from the Eurocentric worldview and drastically shift to a method to identify causal relations. What did Veblen see beyond the proposed revisions? These were the serious problems concerning the individual as well as social welfare, which did not emerge until economic phenomena were considered from the viewpoint of the qualitative category.

For example, Veblen highlighted the problem of value unmeasured by money despite being intimately linked with people's utility and happiness. Additionally, he showed a possibility that a quest for efficiency is serviceable for society in one case and disserviceable in another because efficiency depends on the motives of the actor. $\mathrm{He}$ also provided a tool to explain the causes of business cycles and depression, an area in which the neo-classical economists of that day had proved weak, in addition to redefining capital, assets, cost, technology, and knowledge using the concept of intangibility. Perhaps his idea that industrial arts and knowledge should not be possessed by the individual but managed by the community may have been ahead of his time. ${ }^{33}$ This series of problems was undetected by the quantitative category of economists, although these issues were of utmost importance for the welfare of the society at large.

Veblen's plan for the rehabilitation of economic science may be considered an unusual and particular one in the history of economic thought, and it has not been accepted or ignored. However, the emergence of theoretical interests in the studies

\footnotetext{
${ }^{32}$ One of the most excellent examples of the latter is Hodgson (2008), who concluded that "Veblen's use of Darwinian terminology was not confined to metaphor" because he interpreted it as a meta-theoretical framework (403). In this sense, as Hodgson said, Veblen was one of the first social scientists to apply it to social institutions and structures.

${ }^{33}$ Needless to say, this suggestion leads to our problem of how to solve resource and healthcare-technology nationalism. Protecting the resources of backward countries and reconstructing the more efficient industrial system with international and cosmopolitan characteristics was discussed in the context of Veblen's peace theory.
} 
on economic behavior and the paradox of happiness may reflect the following. If Veblen's anthropological method, which is full of various indigenous peoples' stories, is not always valid, his argumentation, which explains how to overcome the concept of human nature as "economic man," is a persistent problem that receives economists' attention even today.

Acknowledgements A previous version of this paper was presented and discussed at the History of Economic Thought Society of Australia (HETSA) Conference 2017 (26th of September). Though the author used her Japanese-language article (Ishida 2018) with the permission of its editor and publisher, the article was considerably enhanced by adapting it for an international audience. The author would like to thank the participants for their discussions at the HETSA meeting. In addition, she is very grateful to Nihon University for allowing a sabbatical leave, and Carleton College for assisting with the collection and analysis of the materials from the Thorstein B. Veblen Collection in the archives. This work was supported by JSPS KAKENHI Grant Number JP16K03580 and JP17H02506.

Open Access This article is licensed under a Creative Commons Attribution 4.0 International License, which permits use, sharing, adaptation, distribution and reproduction in any medium or format, as long as you give appropriate credit to the original author(s) and the source, provide a link to the Creative Commons licence, and indicate if changes were made. The images or other third party material in this article are included in the article's Creative Commons licence, unless indicated otherwise in a credit line to the material. If material is not included in the article's Creative Commons licence and your intended use is not permitted by statutory regulation or exceeds the permitted use, you will need to obtain permission directly from the copyright holder. To view a copy of this licence, visit http://creativecommons.org/licen ses/by/4.0/.

\section{References}

Almeida F (2015) The psychology of early institutional economics: the instinctive approach of Thorstein Veblen's conspicuous consumer theory. EconomiA 16:226-234. https://doi.org/10.1016/j. econ.2015.05.002

Bloch M (1983) Marxism and anthropology: the history of a relationship. Clarendon Press, Oxford

Carleton College (1880) Annual catalogue of the officers and students of Carleton College, Northfield Minn., For the Academic Year, 1879-80. Pioneer Press Print, Saint Paul

Commons JR (1934) Institutional economics: Its place in political economy. Macmillan, New York

Dorfman J (1934) (1972) Thorstein Veblen and his America with new appendices. Augustus M, Kelley, New York

Hodgson GM (2008) How Veblen generalized Darwinism. J Econ Issues 42(2):399-405. https://doi. org/10.1080/00213624.2008.11507148

Hillemann E (2004) Thorstein Veblen and Carleton College, and vice versa. Paper presented at Carleton College, June 4, 2004, for the 5th Conference of the International Thorstein Veblen Association

Ishida N (2018) "Keizaijin” toiu Ningen Honsei Gainen wo Norikoeru: Veblen's Keizaigaku Rehabilitation Plan (Overcoming the concept of human nature as "Economic Man": Veblen's rehabilitation plan of economics). In: Keizaigaku Hohoron no Tagensei: Rekishiteki Shiten kara (Multidimensional analyses in economic methodology: from a historical perspective). Sotensha, Tokyo

Jensen HE (1987) The theory of human nature. J Econ Issues 21(3):1039-1073

Jorgensen EW, Jorgensen HI (1999) Thorstein Veblen: Victorian firebrand. M. E, Sharpe, Armonk, NY

Marshall A [1890] (1961) Principles of economics. With annotations by CW Guillebaud. 9th (Variorum) Ed. 2 Vols. Macmillan, New York

Mason R (1998) The Economics of conspicuous consumption: Theory and thought since 1700. Edward Elgar Publishing Ltd, Cheltenham

Mayberry TC (1969) Thorstein Veblen on human nature. Am J Econ Sociol 28(3):315-323

Mitchell LS (1953) Two lives: the story of Wesley Clair Mitchell and myself. Simon \& Schuster, New York

Pigou AC (1952) (2002) The economics of welfare. Transaction Publishers, New Brunswick, NJ 
Rutherford M (1996) Institutions in economics: the old and new institutionalism. Cambridge University Press, Cambridge

Samuels WJ (1990) The self-referentiability of Thorstein Veblen's theory of the preconceptions of economic science. J Econ Issues 24(3):695-718. https://doi.org/10.1080/00213624.1990.11505067

Stabile D (1997) The intellectual antecedents of Thorstein Veblen: a case for John Bates Clark. J Econ Issues 31(3):817-825

Taka T (2003) The place of economic man in evolutionary economics: Veblen and Commons reconsidered. Ann Soc Hist Econ Thought 44:17-30. https://doi.org/10.11498/jshet1963.44.17

Tilman R (2007) Thorstein Veblen and the enrichment of evolutionary naturalism. University of Missouri Press, Columbia, MO

Veblen T (1899) The theory of the leisure class: an economic study in the evolution of institutions. Macmillan Company, New York

Veblen T (1904) The theory of business enterprise. Charles Scribner's Sons, New York

Veblen T (1909) The limitations of marginal utility. J Polit Econ 17(9):620-636

Veblen T (1914) The instinct of workmanship and the state of the industrial arts. The Macmillan Company, New York

Veblen T (1919) The place of science in modern civilisation and other essays. New York, B.W, Huebsch

Veblen T (1921) The engineers and the price system. New York, B.W, Huebsch

Publisher's Note Springer Nature remains neutral with regard to jurisdictional claims in published maps and institutional affiliations. 